\title{
RESEARCH
}

Open Access

\section{Measuring spatial accessibility and within- province disparities in accessibility to county hospitals in Shaanxi Province of Western China based on web mapping navigation data}

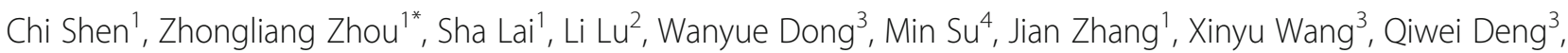
Yaru Chen ${ }^{5}$ and Xi Chen ${ }^{6}$

\begin{abstract}
Background: The Chinese government proposed the "XIAO BING BU CHU CUN, DA BING BU CHU XIAN" initiative in 2016, which states the rate of health care service provided by county hospitals should reach $90 \%$ of overall health care service provision. The prerequisite for achieving this goal is that citizens should be able to access county hospitals' services conveniently and impartially. However, little research has been done on the actual levels of the spatial accessibility of citizens to county hospitals in Western China. Therefore, we aimed to measure the spatial accessibility to county hospitals for county residents and to identify any regional disparities in Shaanxi Province in Western China.

Methods: We implemented a novel method - involving utilizing navigation data from the AutoNavi web mapping system (knows as Gaode map in Chinese) - to assess the time and distance from villages and neighborhoods to the county hospitals. The navigation data were collected by request through an application-programming-interface using a web crawler (web data extraction tool) in Python. The shortest driving time and distance were extracted from the navigation data. The travel impedance to the nearest provider (TINP) indicator was used to measure spatial accessibility.
\end{abstract}

Results: The results show that county residents in Western China's Shaanxi Province have poor spatial accessibility to county hospitals. Only $68.8 \%$ of villages and neighborhoods are within 60 min travel time (based on driving mode) to a county hospital, while $13.4 \%$ of such villages and neighborhoods are beyond 90 min travel time. Moreover, a significant within-province disparity exists, with residents in the central area enjoying the best accessibility to county hospitals, while the northern and southern areas still need improvements in accessibility.

(Continued on next page)

*Correspondence: zzliang1981@163.com

'School of Public Policy and Administration, Xi'an Jiaotong University, No.28 Xianning West Road, Xi'an 710049, Shaanxi, China

Full list of author information is available at the end of the article

(c) The Author(s). 2020 Open Access This article is licensed under a Creative Commons Attribution 4.0 International License, which permits use, sharing, adaptation, distribution and reproduction in any medium or format, as long as you give appropriate credit to the original author(s) and the source, provide a link to the Creative Commons licence, and indicate if changes were made. The images or other third party material in this article are included in the article's Creative Commons licence, unless indicated otherwise in a credit line to the material. If material is not included in the article's Creative Commons licence and your intended use is not permitted by statutory regulation or exceeds the permitted use, you will need to obtain permission directly from the copyright holder. To view a copy of this licence, visit http://creativecommons.org/licenses/by/4.0/. The Creative Commons Public Domain Dedication waiver (http://creativecommons.org/publicdomain/zero/1.0/) applies to the data made available in this article, unless otherwise stated in a credit line to the data. 
(Continued from previous page)

Conclusions: Focused health resource planning is required to improve the spatial accessibility to county hospitals and to eliminate regional disparities. Further studies are called for to integrate the navigation data of web mapping systems with GIS methods to the measure spatial accessibility of health facilities in more complex contexts.

Keywords: Spatial accessibility, County hospitals, Web crawler, Navigation

\section{Introduction}

The Chinese government issued an outline of the "Healthy China 2030" plan on October 25, 2016, which aims to improve people's health and re-emphasizes the need to "provide an equal and accessible, systematic and sustainable health service" [1].

Equity and accessibility have become two of the most important goals of China's health system. Equity and accessibility mean there should be no differences between urban and rural areas, different regions, and populations in terms of health service utilization, health outcomes, and access to health resources ${ }^{1}$ [5]. Here, accessibility generally refers to spatial accessibility (the convenience to reach a health care institution) and economic accessibility (whether the health care is affordable or not) in China [6]. Spatial accessibility not only measures the utilization of health services, but also can affect residents' health status and health service needs [7, 8]. Measurement of the spatial accessibility of health resources may provide effective evidence for the need for health resource reallocation and improved regional health planning.

Existing studies on the spatial accessibility of health resources in China can be mainly summarized into two types based on their focus. First, studies have assessed the spatial accessibility of residents to different types of health institutions from the perspective of health system research. These studies have revealed that the distribution of hospital beds at the county level is highly spatially clustered [9]. Clear gaps in spatial access to primary health care were found within Sichuan Province in China [10], where $69 \%$ of villages have lower spatial accessibility to health services compared with the average county level in Jiangsu Province [11], while the spatial accessibility of public hospitals in Beijing was improved by referral reform in 2015, which also increased the

\footnotetext{
${ }^{1}$ Accessibility of health services has been widely studied and can be understood from different aspects, while there is no consistent on its definition and evaluation [2]. Penchansky and Thomas proposed that access to health services can be divided into five categories: availability, accessibility, accommodation, affordability, and acceptability [3]. These five aspects were considered to be the main influencing factors of health service utilization according to the behavioral model of Andersen's health service utilization [4]. The access to health services was also assessed from four aspects: (1) affordability; (2) physical accessibility; (3) acceptability of services; and (4) not merely adequacy of supply [5].
}

inequality of access to medical resources between towns and streets [12]. Second, some studies have implemented various methods to evaluate the feasibility of using these methods to measure special accessibility, such as the "two-step optimization for spatial accessibility improvement" has been verified can balance the dual goals of efficiency and equality by combining the two steps in a true hybrid optimization model [13], and the two-steps floating catchment area method was verified to be able to reveal detailed spatial distribution differences in larger areas (such as cities) [14]. In conclusion, the spatial accessibility of health resources is a popular research fieldin China, with researchers tending to measure spatial accessibility from the perspective of health systems and methodologies. However, studies from the perspective of health systems are not enough, especially in terms of county-level hospitals.

China's health care delivery system shows an urbanrural dual structure, with the three-tier health care delivery system playing the most important role in providing accessible and sustainable basic health services in rural areas of China [1, 10]. County-level hospitals are the highest level of health care institutions in the county regions, and therefore appropriate accessibility to countylevel hospitals is an important prerequisite for supporting the health needs of rural residents [15]. The Chinese government proposed the "XIAO BING BU CHU CUN, DA BING BU CHU XIAN" initiative in 2016, which means the rate of health care service provided by county hospitals should reach $90 \%$ of overall health care service provision [16]. The prerequisite for achieving this goal is that residents should be able to access health care services from county hospitals conveniently and impartially. However, there is a lack of research documenting the level of spatial accessibility of county hospitals in China.

The commonly used methods to measure residents' spatial accessibility to public services are provider-topopulation ratios (PPR), nearest-neighbor analysis (NNA), and two-step floating catchment area (2SFCA), as well as a series of modified methods [2, 10, 17-19]. There are two main problems in the measurement of spatial accessibility: i) identification of the population distribution, and ii) accurate calculation of the time and distance between residential areas and the health care institutions serving them. The most widely used solutions to obtain population distribution include 1) using 
population census $[8,11,20-22]$, or 2) using a GIS package to cut the map into grid cells with different areas and then to evenly assign the total population of the area to each grid unit and treat its center as the population distribution coordinate point $[7,9,23]$. The most common method to measure time and distance between points is to use road networks in the GIS package together with information on the applicable speed limit criteria on those road networks to measure travel time $[7,9,23]$. Some limitations of this approach include that the traditional census is conducted at intervals and therefore includes hysteresis, that errors can occur from cutting up the map, and that using road network maps can lead to rough estimates.

Therefore, this study aimed to measure spatial accessibility to county hospitals and any disparities in accessibility for county residents in 73 administrative counties in Shaanxi Province of Western China. We first used the navigation data of online digital maps to assess the time and distance from residents to county hospitals in Shaanxi Province. The navigation data were collected from AutoNavi, a Chinese web mapping, navigation, and location-based services provider, via our request to open an application programming interface (API) using web crawler technology.

\section{Data collection and methods Research area}

Shaanxi Province is the most developed province in Western China, with an area of $205,800 \mathrm{~km}^{2}$ and a total population of 38.35 million in 2017 [24]. Geographically, the central, southern, and northern regions of Shaanxi Province differ significantly. The central part is on a plain and includes the wealthiest area in Shaanxi Province, while the southern part includes the Qinling Mountains, and the northern part covers the Loess Plateau. The economy is less developed with a relatively small population density in the southern and northern parts. This study divides Shaanxi Province into three regions based on geographic and economic conditions.

\section{Data collection scheme}

In order to measure the spatial accessibility to health resources, three types of data were basically needed: geographical distribution of the population, the geographical location of hospitals, and the time and distance between residents and the hospitals. Therefore, we collected data in three steps.

First, considering the uneven distribution of the population, we used the geographical location of the villages and neighborhoods to identify the population distribution. Here, two strategies were adopted in our study: i) For villages and neighborhoods with a village clinic, we selected the coordinates of the village clinics to represent the population distribution since the village clinics should be in an area with relatively high concentration of the village population to cover the population of the village to the greatest extent.

ii) For villages and neighborhoods whose village clinic we could not acquire or that have multiple village clinics, we selected the default coordinates provided by the web mapping navigation service provider. This coordinate usually defaults to the location of the village or neighborhood office, which is usually located in a populated area.

Second, we obtained the names of the county hospitals from the Health Commission of Shaanxi Province, and then we directly used the names of the hospitals to get their geographical locations from the web map.

Third, the time and distance between each village and neighborhood to the county hospitals were collected from the navigation results provided bythe web mapping navigation service. We chose the fastest route, but not the highway route (because China's highway import and export are usually set around the county), to get the time and distance from villages and neighborhoods to the local county hospital by using the real-time navigation data of the AutoNavi map in the driving mode. The reason why only the local county hospitals were selected is that the Chinese new rural cooperative medical insurance implemented in rural areas provides cover at the county level only. In this study, we assumed that due to the medical insurance reimbursement strategy, residents were less likely to visit a doctor in another county-level hospital outside their own county [11].

\section{Data collection method}

To perform the data collection, first, we obtained the names of the village clinics and county hospitals in overall Shaanxi Province from the Shaanxi Provincial Health Statistics Annual Report in 2017, which was provided by the Health Commission of Shaanxi Province. In addition, we also obtained the names of the village and neighborhood committees in overall Shaanxi Province from the website of the National Bureau of Statistics [25].

Second, we used the geocoding interface of AutoNavi map to collect the coordinates of all the villages and neighborhoods and county hospitals. The requests through the API for the geocoding of the AutoNavi map were conducted by using a web crawler (a web data extraction tool) in the Python 3.6 program [26]. The URL of this geocoding interface can be found in the footnote below. ${ }^{2}$ AutoNavi map, known as Gaode in Chinese, was

\footnotetext{
${ }^{2}$ https://lbs.amap.com/api/webservice/guide/api/georegeo\#geo
} 
founded in 2011 and is one of the largest web mapping, navigation, and location-based services providers in China. It offers map services at Amap.com and on a mobile App too.

Third, navigation data, including driving time and distance, were collected by using the path planning interface by setting the coordinates of the villages and neighborhoods as the starting point and the coordinates of a county hospital in the district as the endpoint. The URL of the path planning interface can be found in the footnote below. ${ }^{3}$ To consider the influence of the traffic conditions at different times, this study was performed four times randomly: the morning (10:00 to 11:00) and afternoon (14:00 to 15:00) on November 23, 2018 (Friday) and November 27, 2018 (Tuesday). For the time periods studied, crawling requests were made by Python to the AutoNavi mapping for the four time periods, and we took the average value of the results for the four time periods. Finally, data on 10,350 villages and neighborhoods (total of 13,074 villages and neighborhoods) from 73 counties of Shaanxi Province were obtained in our study (Fig. 1).

\section{Analysis methods}

The travel impedance to a nearest provider (TINP) was used to evaluate the spatial accessibility in this study. Here, TINP measured the spatial accessibility by using indicators such as the distance, time, or cost from the place of residence to the nearest medical institution, expressed in terms of a straight Euclidean distance (straight line) [2]. Distance and time were chosem as they are indicators that directly reflect spatial accessibility, whereby the closer the distance, the shorter the travel time and the higher the accessibility. Although TINP ignores the supply of health resources, this method is applicable to situations where the choice of seeking health care service is relatively simple, as in rural areas. In addition, we used more precise traffic distance downloads from a web map instead of the Euclidean distance in this study.

We calculated Getis-Ord Gi* statistics for the spatial association of each county to explore whether there were any disparities in spatial accessibility $[27,28]$. The $\mathrm{Gi}^{*}$ statistic returned for each county was recorded as a zscore [29]. A high positive $\mathrm{z}$-score and small p-value for a county represent a spatial clustering of high values (hot spot)); whereas a low negative $\mathrm{z}$-score and small $\mathrm{p}$ value represent a spatial clustering of low values (cold spot). The higher or lower the z-score, the more intense the clustering. A z-score close to zero means no significant spatial clustering. Getis-Ord $\mathrm{Gi}^{*}$ statistics were calculated by using the R package 'spdep' [30]. The spatial

\footnotetext{
${ }^{3}$ https://lbs.amap.com/api/webservice/guide/api/direction\#driving
}

relationships of counties were defined as Queen's Case. The distance and time of counties were recorded as the averages of distance and time of villages and neighborhoods.

We used concentration curve and the concentration index (CI), a method recommended by the World Bank to measure the inequality in health indicators related to living standards [31], to explore the influence of gross domestic product (GDP) and population on the differences in spatial accessibility to county hospital across counties.

In the concentration curve plot, the horizontal axis is the cumulative percentage of the observation unit (county in our study) ranked in ascending order by living standards (rank variable), and the vertical axis is the cumulative percentage of the health indicator. Originally, the living standard is a socioeconomic indicator, but we extended it to GDP and population. Concentration curve can be used to examine inequality in any health sector variable of interest [31], such as health resources and health services [32, 33].

The value of $\mathrm{CI}$ is the double area between the concentration curve and the line of equality (the 45-degree line); it is a negative (positive) value when the concentration curve lies above (below) the line of equality. The range of $\mathrm{CI}$ is between -1 and 1 , where zero means no rank variable-related inequality, a negative (positive) value means a disproportionate concentration of the health indicator among the observation unit with the lower (higher) value in the rank variable. Generally, the calculation method of the concentration index is as follows:

$$
C=\frac{2}{\mu} \operatorname{cov}(h, r)
$$

where, $h$ is the health indicator, $\mu$ is its mean, and $r$ is the fractional rank of the observation unit. In this study, we selected the average shortest time of the village/ neighborhoods to county hospitals as the health indicator, GDP and population ${ }^{4}$ as the rank variables, and county as the observation unit.

\section{Results}

\section{Level of spatial accessibility}

From the perspective of the villages and neighborhoods level, the average driving distance from the villages and neighborhoods to the county hospitals was $28.4 \mathrm{~km}$, with an average shortest travel time of $49.7 \mathrm{~min}$. Only $68.9 \%$ of villages and neighborhoods are within $60 \mathrm{~min}$ travel time to reach county hospitals, while $13.4 \%$ would

${ }^{4}$ Data were collected from the Shaanxi Statistical Yearbook in 2019. (http://tjj.shaanxi.gov.cn/upload/2020/pro/3sxtjnj/zk/indexch.htm) 


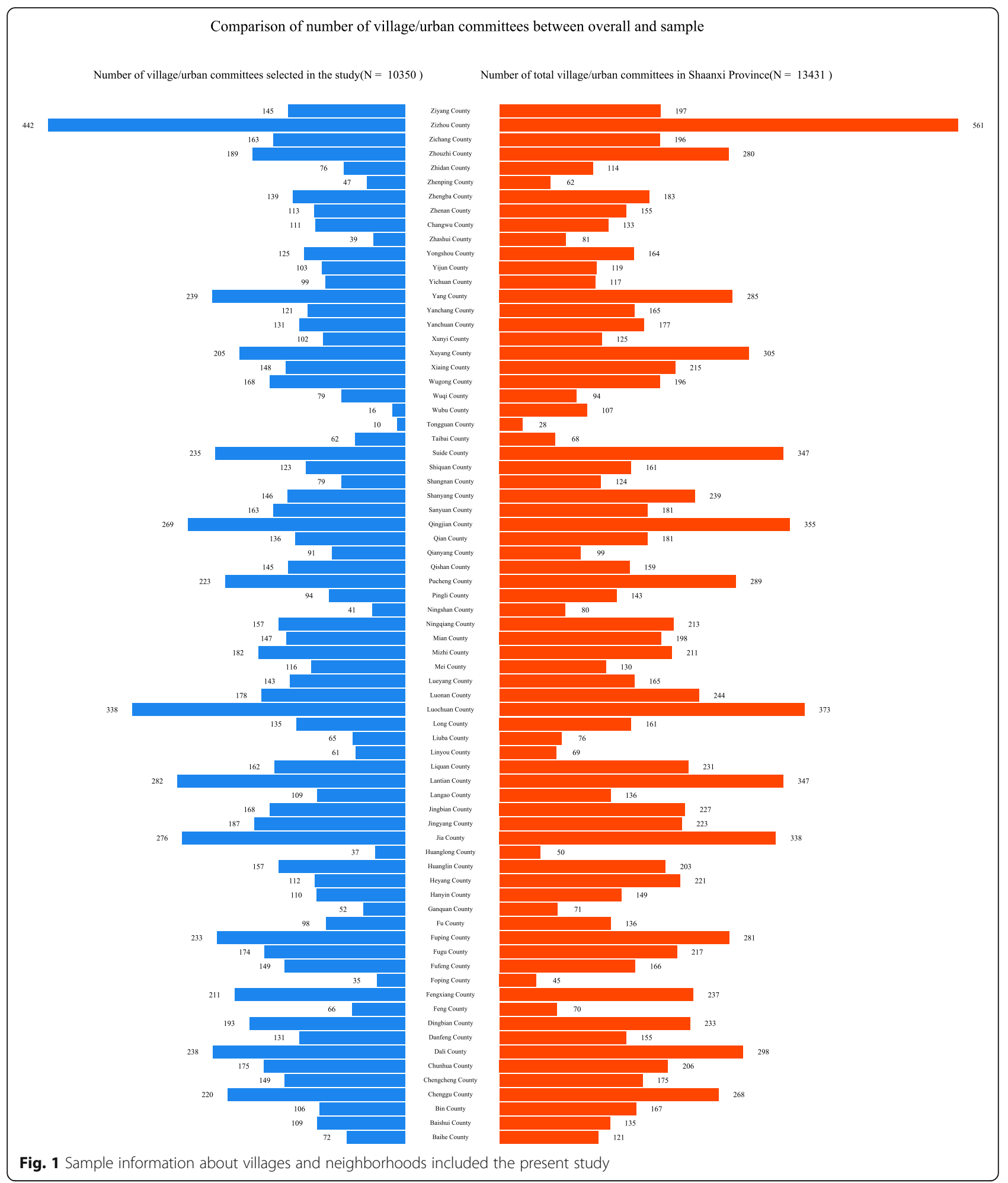

require more than $90 \mathrm{~min}$ to reach the county hospital (Table 2 and Fig. 2).

From the perspective of the county level, we calculated the percentage of villages and neighborhoods where residents could reach county hospitals within $60 \mathrm{~min}$ and
90 min per county. Figure 3 shows that the number of the county where $100 \%$ of villages and neighborhoods can access to the county hospitals within $60 \mathrm{~min}$ and 90 min are 3 and 16, respectively. Therefore, we assumed that the standard measure was one where $80 \%$ of the 


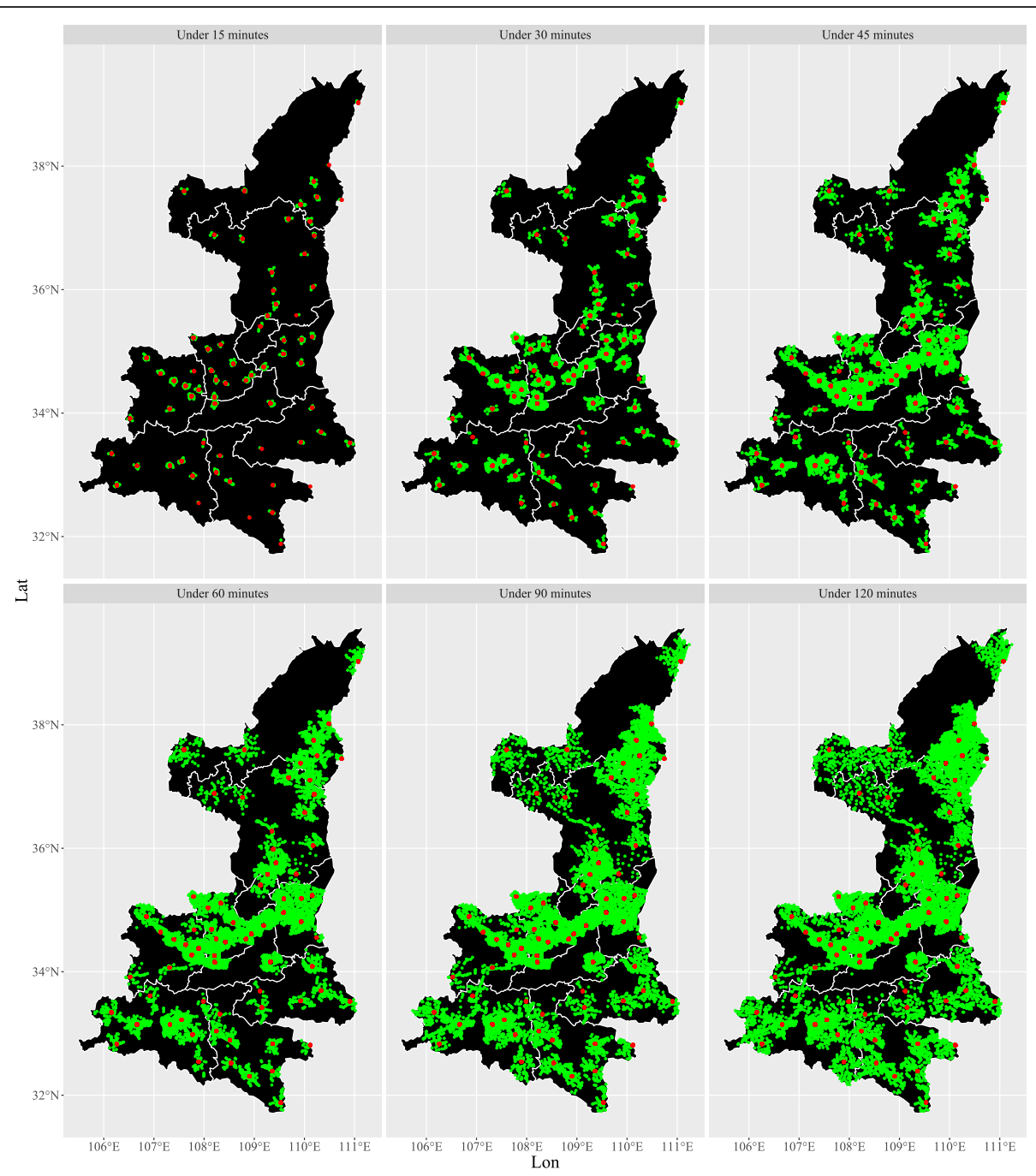

Fig. 2 The distribution of villages and neighborhoods that can reach county hospitals in under different times in Shaanxi Province

villages and neighborhoods were within that travel time limit to reach a county hospital. We further calculated the frequency and percentage of counties in which $80 \%$ of villages or neighborhoods could access a county hospital within $60 \mathrm{~min}$ and $90 \mathrm{~min}$, respectively, and found that only 39.7 and $71.2 \%$ of the counties in Shaanxi Province meet that standard (Table 2).

\section{Disparity of spatial accessibility}

In terms of sub-regions, there is a large disparity of spatial accessibility in the central, northern, and southern regions of Shaanxi Province (Fig. 4). Meanwhile, we summarized the travel distances and times for the individual villages and neighborhoods into county-level values, where the values of each county are the averages of local villages and neighborhoods. Getis-Ord Gi* statistics show that the northern and southern regions of Shaanxi Province are hot areas, while the central region represents a cold area (Fig. 5), which means longer travel distances and times are clustered in the northern and southern regions. In other words, the worst spatial accessibility areas are clustered in the northern and southern regions. The central region has the best spatial accessibility due to its location in the plain and it incorporating richer areas, with an average driving distance from residential areas to county hospitals of $19.2 \mathrm{~km}$ and with the shortest average journey times of $33.5 \mathrm{~min}$, and hence $91.6 \%$ of the residents could reach a county hospital within $1 \mathrm{~h}$ (Table 1). The proportions of residents that can arrive at the county hospitals within one hour in the northern and southern regions were 54.0 and $53.6 \%$, respectively (Table 1 ). At the county level, the proportions where $80 \%$ of the villages and neighborhoods in the counties were within $60 \mathrm{~min}$ travel time to a county hospital were $82.8 \%$ in the central region, $15.0 \%$ in the northern region, and $8.3 \%$ in southern 


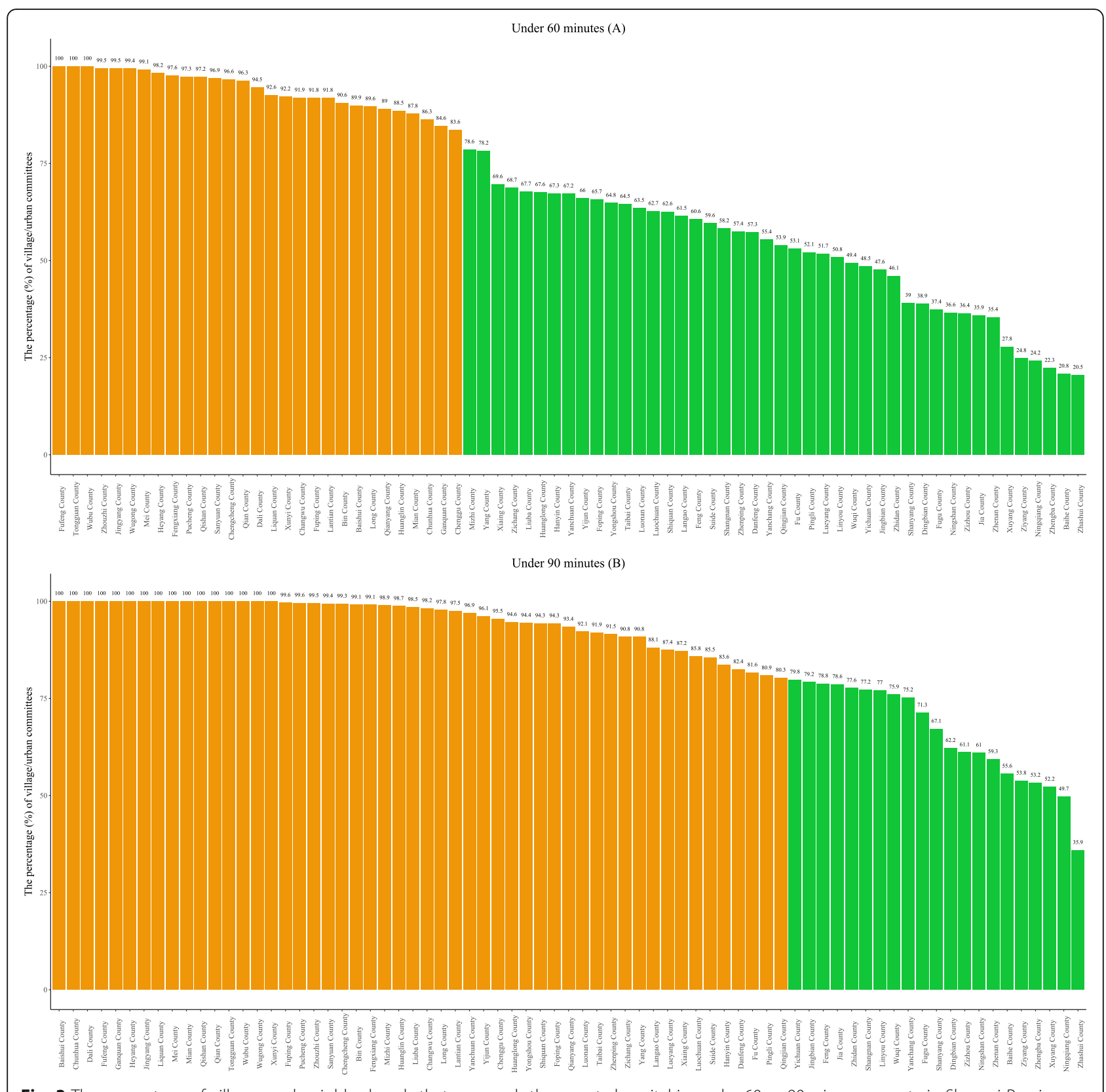

Fig. 3 The percentage of villages and neighborhoods that can reach the county hospital in under 60 or 90 min per county in Shaanxi Province

region. The figures based on arrival within 90 min were only $55.0 \%$ in the northern region and $58.3 \%$ in southern region (Table 2).

\section{Factors influencing the disparities in spatial accessibility} In order to analysis the factors influencing the disparity in spatial accessibility to county hospital across counties, we calculated the concentration index to evaluate whether the population or GDP in a county affect the spatial accessibility to county hospital. The results (Table 3 and Fig. 6) show that the CI for the average shortest time for the village/neighborhood to reach the county hospital in a county, as ranked by population, was -0.059 , which means that counties with smaller populations tend to have a longer travel time to reach the county hospital than counties with larger populations. The CI of the percentage of villages/neighborhoods that can access a county hospital in under $60 \mathrm{~min}$ in a county was 0.070 , which means the county hospitals in the counties with larger populations can cover more residents than the county hospitals in the county with smaller populations. Overall, the residents in a county with a larger population have a higher spatial accessibility to county hospitals. It may seem that the residents in 


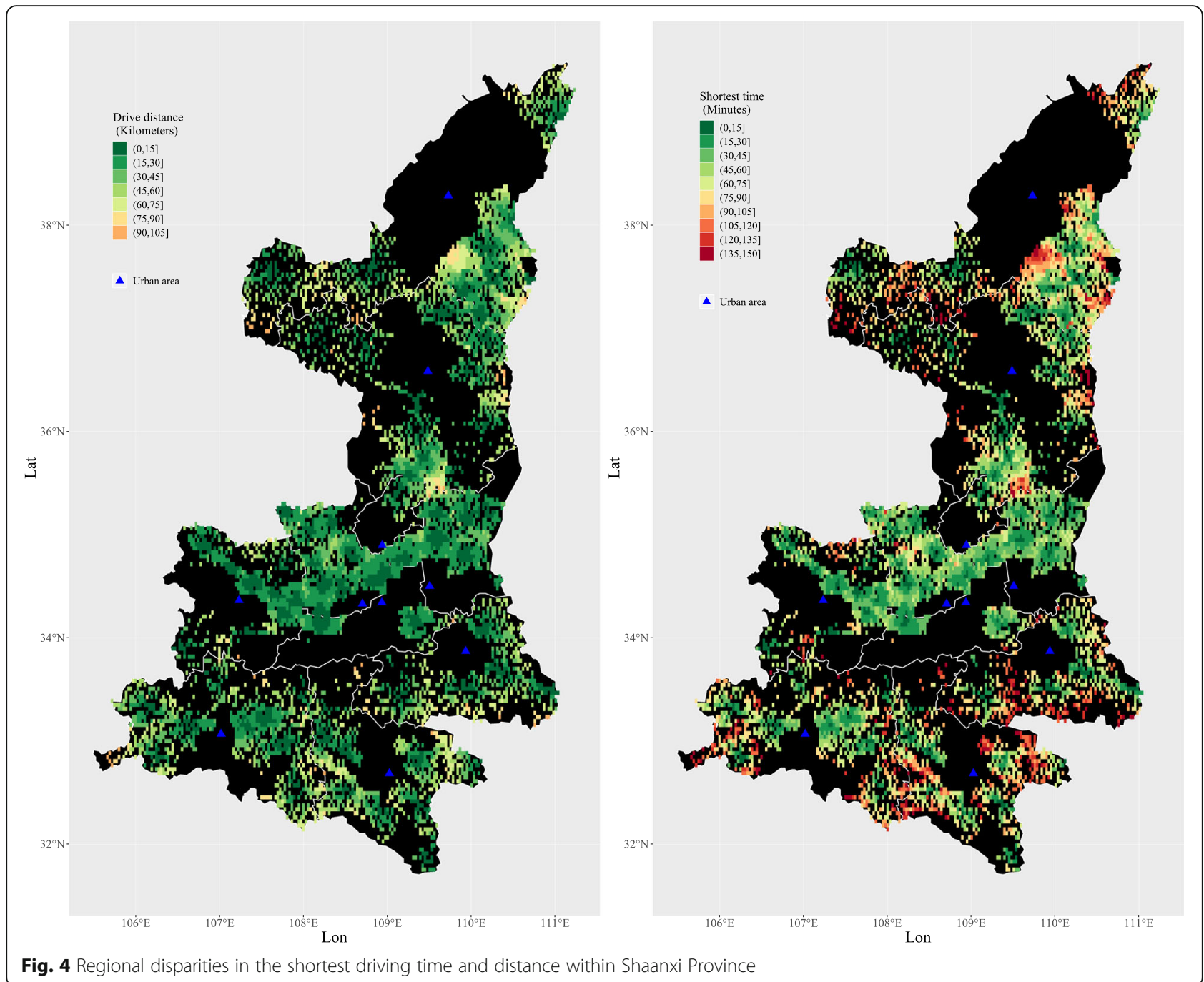

a county with a higher GDP would have higher spatial accessibility to county hospitals too, however, the insignificant p-values did not support us to confirm this finding.

\section{Discussion}

There are three key findings from our study. First, residents in county areas in Shaanxi Province have poor spatial accessibility to county hospitals, whereby only $68.8 \%$ of villages and neighborhoods are within $60 \mathrm{~min}$ travel time to county hospitals, while $13.4 \%$ still need more than $90 \mathrm{~min}$ for residents to reach the county hospital. Second, there is a large disparity within Shaanxi Province, whereby the residents in the central area have the best spatial accessibility to county hospitals, while the northern and southern area still need improvement in the accessibility. Third, residents in counties with a larger population have a higher spatial accessibility to county hospitals. Moreover, our study proved that using the navigation data of a web map to measure spatial accessibility to health resources is a feasible technique.

Our study shows that Shaanxi Province has a low-level spatial accessibility to county-level hospitals. In fact, we think the spatial accessibility might be even worse, because we selected the driving mode to calculate the distance and time in the process of crawling the navigation data. The original intention of selecting the driving mode was to simplify the data collection process; however, in practice, there is a low ownership of moto vehicle pers. 100 urban households, only 29.7 in 2017 in China [34], which means China has not yet developed to the stage where every household has a vehicle, especially in the counties and rural areas. The main travel modes in China's rural areas are motorcycles and e-bikes, which have a lower speed than vehicles, and therefore, the spatial accessibility in the county area may be overestimated in our study. However, this overestimation does not affect the comparisons made here of the spatial accessibility considered under a uniform travel mode, so 


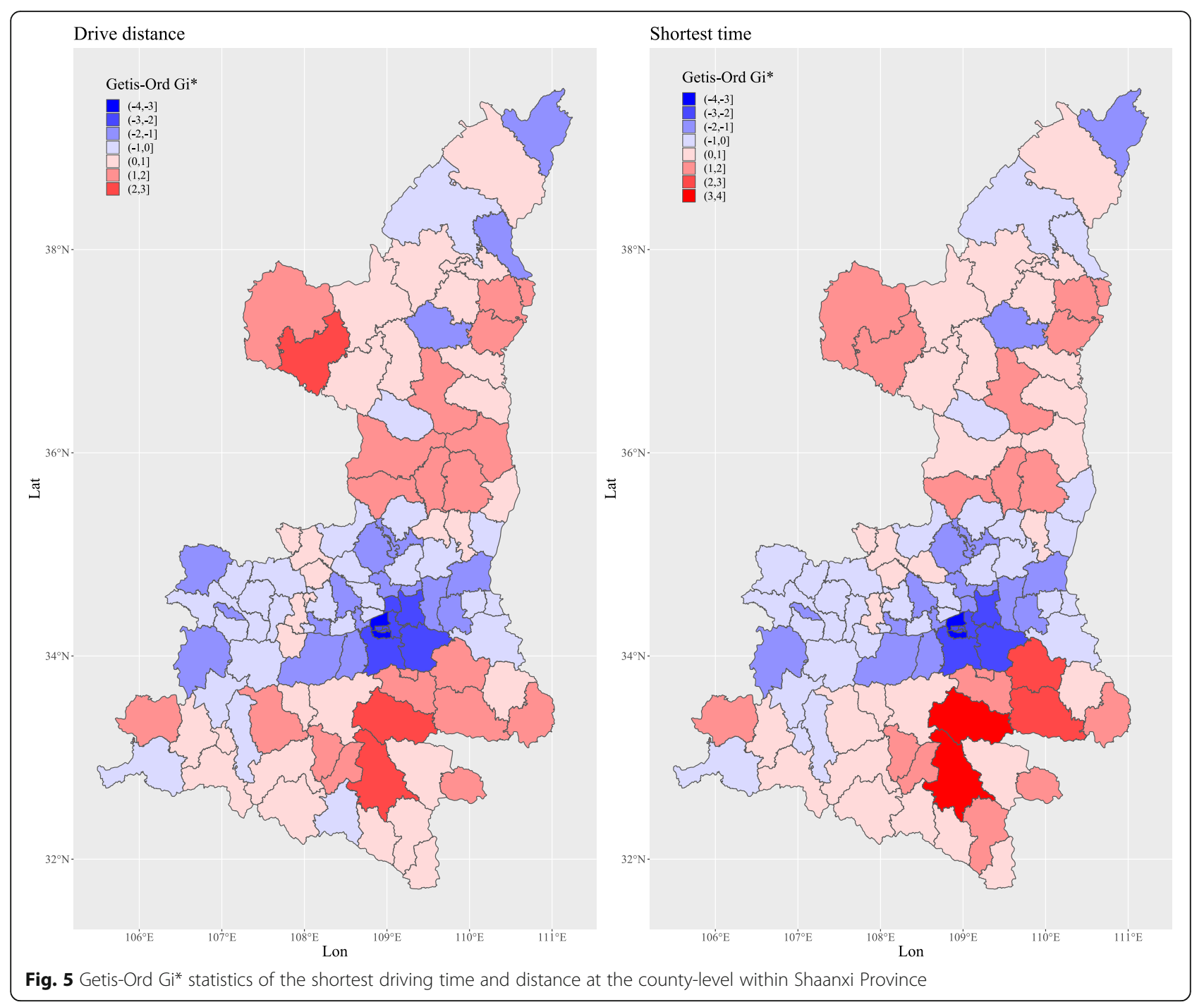

Table 1 Spatial accessibility to county hospitals at the villages and neighborhoods level

\begin{tabular}{|c|c|c|c|c|c|c|}
\hline & Central Shaanxi & Northern Shaanxi & Southern Shaanxi & Overall & $F$ & $p$ \\
\hline $\bar{N}$ & 4119 & 3306 & 2925 & 10,350 & & \\
\hline Distance(km), mean(sd) & $19.2(12.1)$ & $35.2(21.0)$ & $33.8(20.2)$ & $28.4(19.3)$ & 935.7 & $<0.001$ \\
\hline Shortest time(minutes), mean(sd) & $33.5(19.3)$ & $59.5(32.7)$ & $61.5(35.5)$ & $49.7(31.9)$ & 1060 & $<0.001$ \\
\hline \multicolumn{7}{|l|}{ Time range, \%(Cl 95\%): } \\
\hline Under 15 min & $13.8(12.8-14.9)$ & $7.6(6.7-8.5)$ & $6.6(5.7-7.5)$ & $9.8(9.2-10.4)$ & & \\
\hline Under $30 \mathrm{~min}$ & $48.7(47.1-50.2)$ & $21.6(20.2-23)$ & $22.6(21.1-24.1)$ & $32.6(31.7-33.6)$ & & \\
\hline Under $45 \mathrm{~min}$ & $79(77.7-80.2)$ & $38.3(36.6-39.9)$ & $38.9(37.2-40.7)$ & $54.7(53.7-55.6)$ & & \\
\hline Under $60 \mathrm{~min}$ & $91.6(90.8-92.4)$ & $54.0(52.3-55.7)$ & $53.6(51.8-55.4)$ & $68.9(68.0-69.8)$ & & \\
\hline Under $90 \mathrm{~min}$ & $98.3(97.9-98.7)$ & $80.2(78.9-81.6)$ & $77.3(75.8-78.9)$ & $86.6(86.0-87.3)$ & & \\
\hline Under $120 \mathrm{~min}$ & $99.6(99.4-99.8)$ & $95.7(95.0-96.4)$ & $91.9(90.9-92.9)$ & $96.2(95.8-96.5)$ & & \\
\hline
\end{tabular}


Table 2 Spatial accessibility to county hospitals at the county level

\begin{tabular}{lll}
\hline Areas & \multicolumn{2}{l}{ The number (\%) of counties in which 80\% of villages or neighborhoods can access a county hospital } \\
\cline { 2 - 3 } & Under $60 \mathrm{~min}$ & Under $90 \mathrm{~min}$ \\
\hline Overall Shaanxi $(\mathrm{N}=73)$ & $29(39.7 \%)$ & $52(71.2 \%)$ \\
Central Shaanxi $(\mathrm{N}=29)$ & $24(82.8 \%)$ & $27(93.1 \%)$ \\
Northern Shaanxi $(\mathrm{N}=20)$ & $3(15.0 \%)$ & $11(55.0 \%)$ \\
Southern Shaanxi $(\mathrm{N}=24)$ & $2(8.3 \%)$ & $14(58.3 \%)$ \\
\hline
\end{tabular}

comments on the disparity within Shaanxi Province are valid. On the other hand, since Shaanxi is the most developed province in Western China, we have reason to infer that other Western provinces (Gansu and Ningxia, etc.) with less developed economic levels and worse geographical environments may have worse spatial accessibility to county hospitals.

Good spatial accessibility is an important prerequisite for residents to use health care services in a timely manner, whereby a low-level spatial accessibility may cause serval problems. One research study reported that asthma mortality showed a significant trend with an increase in travel time to hospital, and the relative risk was increased by 1.07 times for each additional $10 \mathrm{~min}$ [35]. Mortality from other time-critical diseases, like stroke, may also experience the same risk. Another study showed that geographical obstacles were one of the four major factors limiting persons with disabilities being able to access primary health care [36]. Moreover, we found an obvious regional disparity in the spatial accessibility to county hospitals across Shaanxi Province, and the disparity was highly correlated with the county's population size. This disparity should be taken seriously. Further regional disparities in spatial accessibility were also observed for primary health institutions in Sichuan Province and for public hospitals in Beijing City [10, 12]. Regional variations are also not limited to China and commonly exist in many parts of the world, and have been reported in the literature in various studies, including significant geographic disparities in access to primary stroke centers in the United States [37], in access to health care facilities between urban and suburban seniors in Montreal Island [38], and in access to community resources between urban and rural areas of New Zealand [39]. It is well known that spatial accessibility influences health services utilization. Strong evidence supports that there is a strong pro-rich inequality in maternal health services and inpatient utilization in rural Western China [40, 41]. Accordingly, we have reasons to infer that the disparity in spatial accessibility may cause or aggravate the pro-rich inequality of health services utilization in Western China. Therefore, China should also pay attention to the equity of spatial accessibility to health care, although this may be something the Chinese government is aware of as it has already advocated that residents in every region should have equal access to health care resources.

How to improve the spatial accessibility to county hospitals in rural areas? Some cities in China have begun to set a goal of "15-minute health circle" for primary health care services [42]. Our study identified that it would be reasonable to set the residents' spatial accessibility to county hospitals as " $1 \mathrm{~h}$ " in Western China. In addition, the most direct approach to improve spatial accessibility is to improve transportation facilities in rural areas, but spatial accessibility should not be limited to just making improvements considering the physical distance. By establishing video telemedicine and a timely drug distribution system by using Internet technology to strengthen the flow of superior resources between the three-level (county-township-village) service networks, the spatial distance between residential areas and health care services in county hospitals could also be effectively improved.

Finally, one previous study analyzed the time and space accessibility of urban parks by using the path

Table 3 Concentration Index (Cl) of spatial accessibility to the county hospitals of counties in Shaanxi Province

\begin{tabular}{|c|c|c|c|c|c|c|c|c|}
\hline \multirow[t]{3}{*}{ Interest variable } & \multicolumn{8}{|c|}{ Rank Variable } \\
\hline & \multicolumn{4}{|c|}{ Population } & \multicolumn{4}{|c|}{ GDP } \\
\hline & $\overline{\mathrm{N}}$ & $\mathrm{Cl}$ & Std. Err. & $\overline{p \text { value }}$ & $\bar{N}$ & $\mathrm{Cl}$ & Std. Err. & $p$ value \\
\hline Shortest time ${ }^{a}$ & 73 & -0.059 & 0.024 & 0.015 & 73 & -0.030 & 0.025 & 0.227 \\
\hline Percentage under $60 \mathrm{~min}^{\mathrm{b}}$ & 73 & 0.070 & 0.023 & 0.003 & 73 & 0.037 & 0.024 & 0.119 \\
\hline Percentage under $90 \min ^{c}$ & 73 & 0.016 & 0.012 & 0.183 & 73 & 0.006 & 0.012 & 0.657 \\
\hline
\end{tabular}

a means the average shortest time for villages/neighborhoods in a county, ${ }^{\mathrm{b}}$ means the percentage of villages/neighborhoods that can access the county hospital in under $60 \mathrm{~min}$ in a county, ${ }^{c}$ means the percentage of villages/neighborhoods that can access the county hospital in under 90 min in a county 


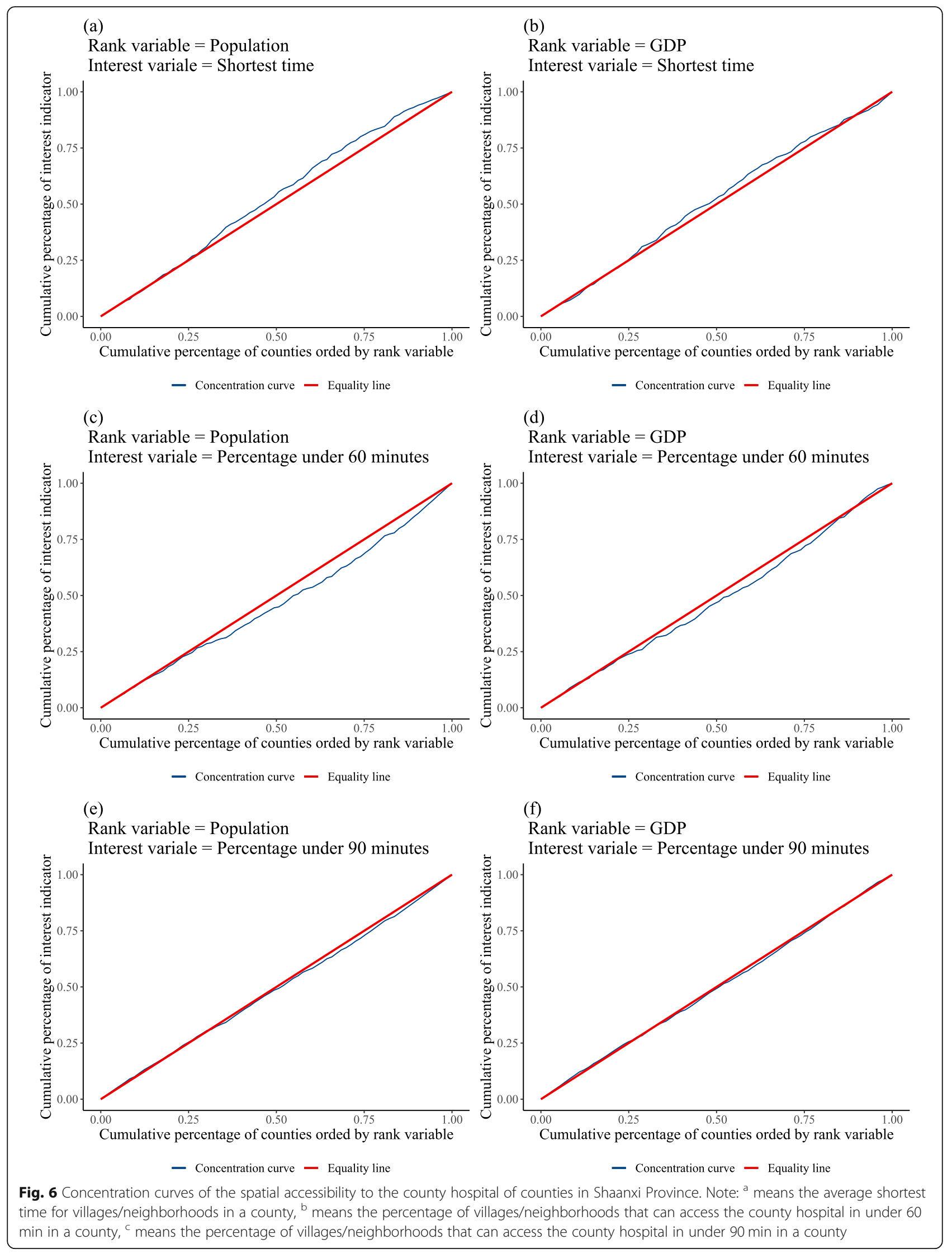


planning API provided by Gaode map [43], as we used in this study, which confirmed the feasibility of using navigation data of the web map to conduct spatial accessibility research. There are two advantages of this method: i) The accuracy of the data extracted from the navigation system is significantly higher than that roughly estimated by using road network maps. However, the measurement accuracy is unsatisfactory whether using the linear Euclidean distance or road network traffic distance. An accurate method to measure distance is very important since the measurement accuracy of the distance directly affects the accuracy of the assessment of spatial accessibility. ii) Navigation data provided by the web mapping realizing real-time updates, i.e., considering the road traffic situation, is more in line with the actual situation. In summary, combining the navigation data from a web map and two-step floating catchment area modified methods to measure spatial accessibility of health resources is highly feasible and has good application prospects.

We still can not avoid there being some limitations in this study, which we note here. First, since it is very difficult to collect specific population data at the village and neighborhood level, only the relatively simple nearest distance method was used to evaluate the spatial accessibility, which ignored the supply and demand of health resources. Second, distance and time data were only extracted under the driving mode, and the figures were not analyzed for using public transportation or other modes, which may not be consistent with the actual mode of travel of rural Chinese residents. Last, not all villages and neighborhoods in Shaanxi Province were involved because a small amount of data were unobtainable. Looking to the future, we are looking for a feasible method to collect the population data in villages and neighborhoods, fortunately, China is doing its sixth national population census, which will provide a chance to obtain accurate population data in villages and neighborhoods. At that time, we can consider the population and health resources for measuring spatial accessibility by combining the navigation data of the web map.

\section{Conclusion}

We found that county residents in Western China's provinces, as represented by Shaanxi Province, have a lower spatial accessibility to county hospitals, and significant regional disparities exist within provinces. Health policy and health resource planning are needed to improve the spatial accessibility and to eliminate regional disparity. Moreover, our study demonstrates the feasibility of using navigation data provided by a web map to measure spatial accessibility to health resources. Further research is needed to verify whether this new method is more accurate than using GIS for evaluation. We encourage further research to combine the navigation data of a web map with two-step floating catchment area modified methods to measure the spatial accessibility of health facilities in more complex situations.

\section{Abbreviations}

API: Application Programming Interface; Cl: Concentration Index; GDP: Gross Domestic Product; NNA: Nearest-Neighbor Analysis; PPR: Provider-toPopulation Ratios; TINP: Travel Impedance to a Nearest Provider; 2SFCA: TwoStep Floating Catchment Area

\section{Acknowledgements}

The authors thank the AutoNavi Software Co., Ltd. for providing application programming interface to download the navigation data freely. We also thank China Scholarship Council for providing financial support to Chi Shen (201906280175) to visit Yale University.

\section{Authors' contributions}

CS, ZLZ and XC contributed to the framework and design of this study. CS and XYW wrote the python script to collect the data and performed the data analysis. CS, LL and SL drafted the manuscript. WYD, JZ, MS and QWD provided assistance in data collection and analysis. YRC provided significant advices in design and analysis. All authors contributed significant intellectual content in this study and approved the final submission.

\section{Funding}

This study was funded by China Medical Board (15-277), National Natural Science Foundation of China (71874137), Shaanxi Social Science Foundation (2017S024), Research Program of Shaanxi Soft Science (2015KRM117), the National high-level talents special support plan (thousands of people plan), Shaanxi provincial youth star of science and technology in 2016, U.S. PEPPER Center Scholar Award (P30AG021342), and two NIH/NIA grants

(K01AG053408; R03AG048920).

\section{Availability of data and materials}

The data were collected from AutoNavi map, a Chinese web map and navigation service provider. This web map provides an open application programming interface for freely using data after registering as a developer. The application programming interface can be found here: (https://lbs.amap. com/api/webservice/guide/api/georegeo\#geo) \& (https://lbs.amap.com/api/ webservice/guide/api/direction\#driving).

Ethics approval and consent to participate

The data used in this study were not collected from human subjects.

Consent for publication

Not applicable.

Competing interests

All authors declare no competing interests.

\section{Author details}

${ }^{1}$ School of Public Policy and Administration, Xi'an Jiaotong University, No.28 Xianning West Road, Xi'an 710049, Shaanxi, China. ${ }^{2}$ Team IETO, Bordeaux Population Health Research Center, University de Bordeaux, 33076 Bordeaux, France. ${ }^{3}$ School of Public Health, Health Science Center, Xi'an Jiaotong University, Xi'an 710063, China. ${ }^{4}$ School of Public Administration, Inner Mongolia University, Hohhot 010021, China. ${ }^{5}$ Centre for HealthCare Innovation Research, Cass Business School \& School of Health Sciences, City, University of London, London EC1V OHB, UK. ${ }^{6}$ Department of Health Policy and Management, Yale School of Public Health, New Haven, CT 06520, USA.

Received: 24 February 2020 Accepted: 10 June 2020

Published online: 18 June 2020

\section{References}

1. General Office of the State Council of China. Outline of the "Healthy China 2030" Program. http://www.gov.cn/xinwen/2016-10/25/content 5124174. htm, Accessed date: 14 March 2019. (In Chinese).. 
2. Guagliardo MF. Spatial accessibility of primary care: concepts, methods and challenges. Int J Health Geogr. 2004;3:3.

3. Penchansky R, Thomas JW. The concept of access: definition and relationship to consumer satisfaction. Med Care. 1981;19:127-40.

4. Andersen RM. Revisiting the behavioral model and access to medical care: does it matter? J Health Soc Behav. 1995:36:1-10.

5. Martin G, Jose FM, Myfanwy M, David H, Barry G, Roger B, Meryl H. What does 'access to health care' mean? J Health Serv Res Policy. 2002;7:186-8.

6. National Health Commission of China. Report on the Fifth National Health Service Survey and Analysis in 2013.http://www.nhfpc.gov.cn/ mohwsbwstjxxzx/s8211/201610/9f109ff40e9346fca76dd82cecf419ce.shtml, Accessed date: 14 March 2019. (In Chinese).

7. Berke EM, Shi X. Computing travel time when the exact address is unknown: a comparison of point and polygon ZIP code approximation methods. Int J Health Geogr. 2009;8:23.

8. Shah TI, Bell S, Wilson K. Spatial accessibility to health care services: identifying under-serviced Neighbourhoods in Canadian urban areas. PLoS One. 2016;11:e0168208.

9. Pan J, Shallcross D. Geographic distribution of hospital beds throughout China: a county-level econometric analysis. Int J Equity Health. 2016;15:179.

10. Wang X, Yang H, Duan Z, Pan J. Spatial accessibility of primary health care in China: a case study in Sichuan Province. Soc Sci Med. 2018;209:14-24.

11. Dong $\mathrm{S}, \mathrm{Li}$ Z, Hu R. Assessing potential spatial accessibility of health services in rural;China: a case study of Donghai county. Int J Equity Health. 2013;12: $1-11$.

12. Lu C, Zhang Z, Lan X. Impact of China's referral reform on the equity and spatial accessibility of healthcare resources: a case study of Beijing. Soc Sci Med. 2019;235:112386

13. Luo J, Tian L, Luo L, Yi H, Wang F. Two-step optimization for spatial accessibility improvement: a case study of health care planning in rural China. Biomed Res Int. 2017:2017:2094654

14. Liu Z, Guo S, Jin H, Xie Z, Wu X, Zhu X. Application of the GIS-based twostep floating catchment area method in measurement of spatial accessibility to hospitals in Beijing. Sci Surveying Mapping. 2007;32:61-3.

15. Office of the State Council of China. National Health Service System Planning Outline (2015-2020). http://www.gov.cn/zhengce/content/201503/30/content_9560.htm, Accessed date: 14 March 2019. (In Chinese).

16. State Council of China. The 13th Five-Year Plan of Health. http://www.gov. cn/zhengce/content/2017-01/10/content_5158488.htm, Accessed date: 14 March 2019. (In Chinese).

17. Neutens T. Accessibility, equity and health care: review and research directions for transport geographers. J Transp Geogr. 2015:43:14-27.

18. Luo W, Whippo T. Variable catchment sizes for the two-step floating catchment area (2SFCA) method. Health Place. 2012:18:789-95.

19. Tao $Z$, Cheng $Y$. Research progress of the two step floating catchment area method and extensions (in Chinese). Prog Geogr. 2016;35:11.

20. Mao L, Nekorchuk D. Measuring spatial accessibility to healthcare for populations with multiple transportation modes. Health Place. 2013;24:115-22.

21. Luo W, Qi Y. An enhanced two-step floating catchment area (E2SFCA) method for measuring spatial accessibility to primary care physicians. Health Place. 2009:15:1100-7.

22. Luo W, Wang F. Measures of spatial accessibility to healthcare in a GIS environment: synthesis and a case study in Chicago region. Environ Plann B Plann Design. 2003:30:865-84.

23. Huotari $T$, Antikainen $H$, Keistinen $T$, Rusanen J. Accessibility of tertiary hospitals in Finland: a comparison of administrative and normative catchment areas. Soc Sci Med. 2017:182:60-7.

24. Shaanxi Province Burean of Statistics. Statistics Yearbook of Shaanxi Province in 2018: Population and Its Composition, http://tjj.shaanxi.gov.cn/ contListCommon_128_1.html, Accessed date: 15 March 2019. (In Chinese).

25. National Burean of Statistics of China. 2017 zoning code and urban and rural division code (as of October 31, 2017), http://www.stats.gov.cn/tjsj/ tjbz/tjyghdmhcxhfdm/2017/index.html, Accessed date: 15 March 2019. (In Chinese).

26. Quan B, Gang X, Yong Z, He L. Analysis and detection of bogus behavior in web crawler measurement. Procedia Comput Sci. 2014;31:1084-91.

27. Getis A, Ord JK. The analysis of spatial association by use of distance statistics. Geogr Anal. 1992;24:189-206.

28. Ord JK, Getis A. Local spatial autocorrelation statistics - distributional issues and an application. Geogr Anal. 1995;27:286-306.
29. de Castro MC, Singer BH. Controlling the false discovery rate: a new application to account for multiple and dependent tests in local statistics of spatial association. Geogr Anal. 2006;38:180-208.

30. Bivand RS, Wong DWS. Comparing implementations of global and local indicators of spatial association. Test. 2018;27:716-48.

31. O'Donnell O, Van Doorslaer E, Wagstaff A, Lindelow M. Analyzing health equity using household survey data. 2007. Washington, DC: The World Bank; 2016.

32. Li D, Zhou Z, Si Y, Xu Y, Shen C, Wang Y, Wang X. Unequal distribution of health human resource in mainland China: what are the determinants from a comprehensive perspective? Int J Equity Health. 2018;17:29.

33. Zhang T, Xu Y, Ren J, Sun L, Liu C. Inequality in the distribution of health resources and health services in China: hospitals versus primary care institutions. Int J Equity Health. 2017;16:42.

34. National Bureau of Statistics of China. Wang You Juan: In 2017, the income of the national residents increased rapidly, and the quality of life of the residents continued to improve. http://www.stats.gov.cn/tjjs/sjjd/201801/t2 0180119_1575491.html, Accessed date: 16 March 2019. (In Chinese).

35. Jones AP, Bentham G, Horwell C. Health service accessibility and deaths from asthma. Int J Epidemiol. 1999;28:101-5.

36. Dassah $E$, Aldersey H, McColl MA, Davison C. Factors affecting access to primary health care services for persons with disabilities in rural areas: a "best-fit" framework synthesis. Glob Health Res Policy. 2018;3:36.

37. Mullen MT, Wiebe DJ, Bowman A, Wolff CS, Albright KC, Roy J, Balcer LJ, Branas CC, Carr BG. Disparities in accessibility of certified primary stroke centers. Stroke. 2014:45:3381-8.

38. Paez A, Mercado RG, Farber S, Morency C, Roorda M. Accessibility to health care facilities in Montreal Island: an application of relative accessibility indicators from the perspective of senior and non-senior residents. Int J Health Geogr. 2010;9:52.

39. Pearce J, Witten K, Bartie P. Neighbourhoods and health: a GIS approach to measuring community resource accessibility. J Epidemiol Community Health. 2006:60:389-95.

40. Liu X, Gao W, Yan H. Measuring and decomposing the inequality of maternal health services utilization in Western rural China. BMC Health Serv Res. 2014;14:102.

41. Zhou Z, Gao J, Fox A, Rao K, Xu K, Xu L, Zhang Y. Measuring the equity of inpatient utilization in Chinese rural areas. BMC Health Serv Res. 2011;11:201.

42. Health.People.cn. Reform about 15-minute medical circle. http://health. people.com.cn/n1/2019/0916/c14739-31354130.html, Accessed date: 16 March 2019. (In Chinese).

43. Huang Y, Liu X, Liu Y, Zhang H. Spatial and temporal accessibility analysis of urban parks based on Amap API by means of multiple transportation:a case study of Haizhu District in Guangzhou. Geography Geo Inform Sci. 2018;34:8 (In Chinese).

\section{Publisher's Note}

Springer Nature remains neutral with regard to jurisdictional claims in published maps and institutional affiliations.

Ready to submit your research? Choose BMC and benefit from:

- fast, convenient online submission

- thorough peer review by experienced researchers in your field

- rapid publication on acceptance

- support for research data, including large and complex data types

- gold Open Access which fosters wider collaboration and increased citations

- maximum visibility for your research: over $100 \mathrm{M}$ website views per year

At BMC, research is always in progress.

Learn more biomedcentral.com/submission 